\title{
Food-Derived Hemorphins Cross Intestinal and Blood-Brain Barriers In Vitro
}

\begin{abstract}
Dorothée Domenger ${ }^{1}$, Benoit Cudennec ${ }^{1 *}$, Mostafa Kouach ${ }^{2}$, Véronique Touche ${ }^{3}$, Christophe Landry ${ }^{4}$, Jean Lesage ${ }^{5}$, Fabien Gosselet ${ }^{4}$, Sophie Lestavel ${ }^{3}$, Jean-François Goossens ${ }^{2}$, Pascal Dhulster ${ }^{1}$ and Rozenn Ravallec ${ }^{1 *}$
\end{abstract}

\begin{abstract}
'Université de Lille INRA, ISA, Université d'Artois, Université Littoral Côte d'Opale, EA 7394-ICV Institut Charles Viollette, Lille, France, ${ }^{2}$ Plateau de Spectrométrie de Masse "PSM-GRITA", EA 7365, Faculté de Pharmacie, Université de Lille, Lille, France, ${ }^{3}$ Université de Lille INSERM, CHU Lille, Institut Pasteur de Lille, U1011 - EGID, Lille, France, ${ }^{4}$ Université d'Artois EA 2465, Laboratoire de la Barrière Hémato-Encéphalique (LBHE), Lens, France, ${ }^{5}$ Université Lille Nord de France, Unité Environnement Périnatal et Croissance EA 4489, Équipe dénutritions maternelles périnatales, Université Lille 1 , Villeneuve-d'Ascq, France
\end{abstract}

OPEN ACCESS

Edited by:

Pierrette Gaudreau,

Université de Montréal, Canada

Reviewed by:

Alexandre Benani,

Centre national de la recherche scientifique (CNRS), France

Ben Nephew,

Tufts University Cummings School of Veterinary Medicine, United States

*Correspondence:

Benoit Cudennec

benoit.cudennec@univ-lille.fr;

Rozenn Ravallec

rozenn.ravallec@univ-lille.fr

Specialty section:

This article was submitted to

Neuroendocrine Science,

a section of the journal

Frontiers in Endocrinology

Received: 09 December 2017

Accepted: 26 March 2018

Published: 10 April 2018

Citation:

Domenger D, Cudennec $B$ Kouach M, Touche V, Landry C, Lesage J, Gosselet F, Lestavel S, Goossens J-F, Dhulster $P$ and Ravallec $R$ (2018) Food-Derived Hemorphins Cross Intestinal and Blood-Brain Barriers In Vitro.

Front. Endocrinol. 9:159. doi: 10.3389/fendo.2018.00159
A qualitative study is presented, where the main question was whether food-derived hemorphins, i.e., originating from digested alimentary hemoglobin, could pass the intestinal barrier and/or the blood-brain barrier (BBB). Once absorbed, hemorphins are opioid receptor (OR) ligands that may interact with peripheral and central $\mathrm{OR}$ and have effects on food intake and energy balance regulation. LLV-YPWT (LLW-H4), LV-H4, V-H4, W-YPWTQRF (V-H7), and W-H7 hemorphins that were previously identified in the 120 min digest resulting from the simulated gastrointestinal digestion of hemoglobin have been synthesized to be tested in in vitro models of passage of IB and BBB. LC-MS/ MS analyses yielded that all hemorphins, except the LLVV-H4 sequence, were able to cross intact the human intestinal epithelium model with Caco-2 cells within 5-60 min when applied at $5 \mathrm{mM}$. Moreover, all hemorphins crossed intact the human BBB model with brain-like endothelial cells (BLEC) within 30 min when applied at $100 \mu \mathrm{M}$. Fragments of these hemorphins were also detected, especially the YPWT common tetrapeptide that retains OR-binding capacity. A cAMP assay performed in Caco-2 cells indicates that tested hemorphins behave as OR agonists in these cells by reducing cAMP production. We further provide preliminary results regarding the effects of hemorphins on tight junction proteins, specifically here the claudin-4 that is involved in paracellular permeability. All hemorphins at $100 \mu \mathrm{M}$, except the LLVV-H4 peptide, significantly decreased claudin-4 mRNA levels in the Caco-2 intestinal model. This in vitro study is a first step toward demonstrating food-derived hemorphins bioavailability which is in line with the growing body of evidence supporting physiological functions for food-derived peptides.

Keywords: opioid peptides, hemorphins, intestinal barrier, blood-brain barrier, Caco-2 model, brain-like endothelial cell model, claudin-4, cAMP

\section{HIGHLIGHTS}

- Food-derived hemorphins cross intestinal barrier in vitro.

- Food-derived hemorphins cross human blood-brain barrier (BBB) in vitro.

- New hemorphin sequences behave as opioid receptor (OR) agonists in Caco-2 cells. 
- Food-derived hemorphins modulate claudin-4 mRNA levels in Caco-2 cells.

- Naloxone behaves as OR agonist in Caco-2 cells.

\section{INTRODUCTION}

Hemorphins are a group of opioid peptides encrypted in the beta-chain of hemoglobin, in a conserved region between bovine and human hemoglobin. Hemorphins, from endogenous or food-derived hemoglobin, are found in many different tissues and species (1-3) and many bioactivities have been uncovered for these hemorphins, notably in blood pressure regulation (4-6) and cognitive functions (7). They were first shown to interact with opioid receptors (ORs) $(8,9)$ that earned them the name "hemorphin," and explain other activities like intestinal peristalsis $(10,11)$, bladder contraction, inflammation, and pain modulation $(12-14)$. Our laboratory is interested in the fate of alimentary or digested hemoglobin protein and particularly in the derived bioactive peptides thereof in relation to food intake regulation. We have previously identified five hemorphins from the simulated gastrointestinal digestion of hemoglobin. This simulated gastrointestinal digestion has been validated (15) and is now routinely used to identify and highlight bioactivities of food-derived peptides. These five hemorphins that were produced by and resistant to gastrointestinal digestion have been studied for their effects at the intestinal lumen level in relation to gut hormones synthesis and release and DPP-IV (CD26) regulation (16). Among these five hemorphins (Table 1), three have an $\mathrm{N}$-terminal extension, LLVV-, LVV-, and VV-, one has a C-terminal extension, -QRF, and one has both an N-terminal, VV- and C-terminal -QRF, extension of the tetrapeptide core YPWT that has been demonstrated to bind to OR.

Opioid receptors are involved in many aspects of food intake regulation via central effects (17). Recently, peripheral ORs have also been involved in these regulations and a gut-brain loop has been described with a crucial role of the portal vein mu-OPs (18). It was thus proposed that opioid peptides originating from the digestion and absorption of dietary proteins would interact with the OR located in the portal vein and trigger a gut-brain loop mediating high-protein diet-induced satiety.

Given hemorphins size and evidence from the literature for other exorphins (19), it is likely that the passage of these peptides belongs to the paracellular transport mode involving effects on tight junction (TJ). Moreover, there is some literature implicating opioids in intestinal permeability disorders and TJ regulation. There are known deleterious effects of mu-OR agonists on the gut barrier and immune function in pain-treated patients or drug abusers $(20,21)$. In mice, it was shown that morphine treatment is associated with disruption of TJ organization (22). TJ proteins are an ensemble of protein families that seal the paracellular space between epithelial cells. TJ proteins include transmembrane proteins, such as occludin and claudin families, and scaffolding proteins, such as zonula occludens-1 (ZO-1) and -2 (ZO-2).

Hence, we sought, by using two in vitro models, to demonstrate that food-derived hemorphins, intact or as fragments retaining OR-binding capacity, pass the intestinal and the BBBs. For the IB, Caco-2 was used as a well recognized and widely used model of human intestinal epithelium $(23,24)$. Indeed, according to the Biopharmaceutics Classification System, there is a high correlation between Caco- 2 cell permeability coefficients and fractional absorption values in humans (25). Moreover, especially interesting in the present study where the BBB passage has also been tested, the Caco-2 model revealed to be predictive of oral bioactivity and of BBB permeability (26), although another study concluded to a poor correlation between Caco-2 cell data and in vivo $\mathrm{BBB}$ transport (27). Several BBB models have been described over the past 40 years and are currently used in different research groups to analyze different aspects of BBB biology and drug targeting. The human brain-like endothelial cells (BLEC) co-culture model recently described (28) was chosen in this study. It expresses TJ and transporters typically observed in brain endothelium, displays most in vivo BBB properties and thus could be used for both mechanistic studies and as a screening tool for CNS-compound permeability studies in human $(29,30)$.

We report here the results of both in vitro intestinal and BBB passage tests, analyzed by LC-MS/MS, of five food-derived hemorphins and preliminary results of hemorphins impact on $\mathrm{TJ}$ proteins of the IB.

\section{MATERIALS AND METHODS}

\section{Chemicals}

Dulbecco's modified eagle's medium (DMEM) with high glucose (4.5 $\mathrm{g} \mathrm{L}^{-1}$ ), fetal bovine serum (FBS), Dulbecco's phosphate buffered saline, Hank's balanced salt solutions (HBSS), lucifer yellow (LY), Bestatin, thiorphan, naloxone, DAMGO, forskolin (FK), and Whatmann GF/B glass microfiber filter were purchased from Sigma-Aldrich (Steinheim, Germany). L-Glutamine and

TABLE 1 | Passage of five hemorphins identified in the intestinal fraction of (in vitro) gastrointestinal digests of hemoglobin, through the intestinal barrier (IB) (caco-2 model) and blood-brain barrier (BBB) (co-culture model of hematopoietic CD34+-derived endothelial cells with brain pericytes) in vitro.

\begin{tabular}{|c|c|c|c|}
\hline Hemorphins applied & \multicolumn{2}{|c|}{ Intestinal barrier } & $\frac{\text { BBB }}{\text { Basal }}$ \\
\hline LLW-H4 & LLV-H4, LW-H4, W-H4, H4 & $\mathrm{H} 4$ & $\mathrm{H} 4, \mathrm{~W}-\mathrm{H} 4, \mathrm{LW}-\mathrm{H} 4$, LLV-H4 \\
\hline W-H4 & $\mathrm{W}-\mathrm{H} 4, \mathrm{H} 4$ & $\mathrm{H} 4, \mathrm{~W}-\mathrm{H} 4$ & $\mathrm{H} 4, \mathrm{~W}-\mathrm{H} 4$ \\
\hline $\mathrm{W}-\mathrm{H} 7$ & $\mathrm{~W}-\mathrm{H} 7, \mathrm{~W}-\mathrm{H} 4, \mathrm{H} 7, \mathrm{H} 6$ & $\mathrm{H} 4, \mathrm{~W}-\mathrm{H} 7, \mathrm{H} 7, \mathrm{H} 3$ & $\mathrm{H} 4, \mathrm{~W}-\mathrm{H} 7, \mathrm{~W}-\mathrm{H} 4, \mathrm{H} 7, \mathrm{H} 3, \mathrm{H} 5$ \\
\hline $\mathrm{H} 7$ & $\mathrm{H} 7, \mathrm{H} 6, \mathrm{H} 4, \mathrm{H} 3$ & $\mathrm{H} 4, \mathrm{H} 7, \mathrm{H} 3$ & $\mathrm{H} 4, \mathrm{H} 7, \mathrm{H} 3, \mathrm{H} 5$ \\
\hline
\end{tabular}

Five hemorphins, LLW-H4 (LLW-YPWT), LW-H4 (LLW-YPWT), W-H4 (WV-YPWT), W-H7 (W-YPWTQRF), and H7 (YPWTQRF) have been applied separately in the apical side of epithelium in each passage test. This table sums up the presence of the intact peptides or their fragments in each compartment at the end of the 120 min passage test. 
penicillin-streptomycin were from Pan-Biotech (Aidenbach, Germany). Cell culture inserts with polycarbonate membranes (3 $\mu \mathrm{m}$ pore size; $4.2 \mathrm{~cm}^{2}$ surface area and $0.4 \mu \mathrm{m}$ pore size; $1.12 \mathrm{~cm}^{2}$ surface area) and companion plates were purchased from Corning (Boulogne-Billancourt, France). H3-naloxone and the scintillation liquid Optiphase HiSafe 2 was obtained from PerkinElmer (Courtaboeuf, France). For the determination of intracellular CAMP, the Mouse/Rat cAMP Parameter Assay Kit was used (R\&D Systems, Bio-Techne, Lille, France). Protein dosage assays were performed with the Sigma QuantiPro BCA Assay Kit (Sigma-Aldrich, Steinheim, Germany) or the Pierce BCA Protein Assay Kit (Thermo Fisher Scientific, Saint-Aubin, France). Reagents for the preparation and performance of quantitative real-time PCR (qPCR) were TRI Reagent ${ }^{\circledR}$ (SigmaAldrich, Steinheim, Germany), RevertAid H Minus First Strand cDNA Synthesis Kit and the Power SYBR Green PCR Master Mix (Thermo Fisher Scientific, Saint-Aubin, France). Specific oligonucleotides were purchased from Eurogentec (Seraing, Belgium). Synthetic peptides were purchased from GeneCust (Dudelange, Luxemburg).

\section{Cell Culture}

For the cAMP determination assay and the gene expression study, the cell line used was the Caco- 2 cell line purchased from Sigma-Aldrich (Steinheim, Germany). Cells were grown at $37^{\circ} \mathrm{C}$, $5 \% \mathrm{CO}_{2}$ atmosphere in Dulbecco's modified Eagle's Medium (DMEM, $4.5 \mathrm{~g} \mathrm{~L}^{-1}$ glucose) supplemented with 10\% FBS, $2 \mathrm{mM}$ L-glutamine, $100 \mathrm{U} \mathrm{mL}^{-1}$ penicillin, and $100 \mu \mathrm{g} \mathrm{mL}^{-1}$ streptomycin (complete DMEM) until use. Caco-2 from passages 34-37 were used. For the transport studies, the cell lines used and the culture protocols conditions are described in detail in dedicated subsections below.

\section{Transport Studies \\ In Vitro Human IB Model}

The human intestinal cell line used for the transport experiments was the Caco-2/TC7 clone, a gift from Dr. Monique Rousset (UMRS 872, INSERM, Paris). Cells were routinely grown as previously described (31). For the experiment, they were seeded at the density of $60 \times 10^{3}$ cells $\mathrm{cm}^{-2}$ into cell culture inserts in 6 -well culture plates and grown for 21 days.

The day of the trans-intestinal transport test, growth media were removed, and cells were first rinsed with the transport medium, HBSS-Hepes buffer supplemented with $\mathrm{CaCl}_{2}(2.5 \mathrm{mM}$ final $)$ and $\mathrm{MgCl}_{2}(0.5 \mathrm{mM}$ final $)$ in the apical $(1 \mathrm{~mL})$ and basolateral chambers $(2.5 \mathrm{~mL})$, then pre-incubated for $30 \mathrm{~min}$ with the transport medium. All incubations were performed at $37^{\circ} \mathrm{C}, 10 \% \mathrm{CO}_{2}$ atmosphere. To control the integrity of the Caco-2/TC7 cell barrier, the paracellular transport marker lucifer yellow (LY, $100 \mu \mathrm{M}$ final) was applied apically into each well and its transport into the basolateral chamber was monitored by spectrofluorescence. Each hemorphin was diluted for a final concentration of $5 \mathrm{mM}$ in transport medium-LY and applied to the apical chamber at $\mathrm{t} 0$. In parallel, control wells were incubated with transport medium-LY only and all conditions were tested in triplicate. At t5, 15, 30, and $60 \mathrm{~min}, 100 \mu \mathrm{L}$ samples were collected in the basal chamber and replaced by the same volume of transport medium. At $\mathrm{t} 120 \mathrm{~min}$, all remaining media in basal and apical chambers were collected and all samples were stored at $-80^{\circ} \mathrm{C}$. The rate of LY transport was determined by fluorescence readings (ex 485/em $530 \mathrm{~nm}$ ) at each time point on the spectrofluorometer Safas Xenius XC (Safas Monaco, Monaco, France) and calculating the apparent permeability coefficient (Papp) as follows: $(\Delta \mathrm{Q} / \Delta \mathrm{t}) \times(\mathrm{Vb} /(\mathrm{A} \times \mathrm{C} 0))$, where $\Delta \mathrm{Q}$ is the change in LY concentration in the basal chamber $(\mu \mathrm{M}) ; \Delta \mathrm{t}$ is the transport duration $(\mathrm{s}) ; \mathrm{Vb}$ is the volume in the basal chamber $(\mathrm{mL})$; $\mathrm{A}$ is the surface area of the insert/transwell membrane $\left(\mathrm{cm}^{2}\right)$; and $\mathrm{C} 0$ is the initial concentration of LY applied to the apical chamber $(\mu \mathrm{M})$. Papp is measured in $\mathrm{cm} \mathrm{s}^{-1}$ and the Caco-2/TC7 cell barrier for each sample was considered intact if Papp $<1 \times 10^{-6} \mathrm{~cm} \mathrm{~s}^{-1}$.

\section{In Vitro Human BBB Model: BLEC Model}

The brain-like endothelial cell model has previously been described in detail (28). All the sample donors had given their written informed consent, in compliance with French legislation and the 2013 version of the Declaration of Helsinki. The sample collection was approved by the local investigational review board (Bethune Maternity Hospital Béthune, France). Briefly, this human model consists in isolating CD34+ cells from umbilical cord blood. These cells are then cultured in endothelial cell medium supplemented with 20\% FCS for 15-20 days. After this period, cells are differentiated into endothelial cells. After a trypsinization step, they are seeded on matrigel coated-transwell inserts in 12-well culture plates, and subsequently cultured with brain pericytes, isolated from bovine brain capillaries. After 6 days of co-culture, human endothelial cells acquire the $\mathrm{BBB}$ phenotype, and are then named BLECs.

The day of the transport test, the same procedure as for the intestinal passage assay was applied except that the transwell inserts were transferred to a new 12 -well culture plate at each time point, 30, 60, 90, and $120 \mathrm{~min}$. All incubations were performed at $37^{\circ} \mathrm{C}, 5 \% \mathrm{CO} 2$ atmosphere with slight agitations. The transport medium consisted in Ringer-Hepes solution $(150 \mathrm{mM}$ $\mathrm{NaCl}, 5.2 \mathrm{mM} \mathrm{KCl}, 2.2 \mathrm{mM} \mathrm{CaCl} 2,0.2 \mathrm{mM} \mathrm{MgCl}_{2} \cdot 6 \mathrm{H}_{2} \mathrm{O}, 6 \mathrm{mM}$ $\mathrm{NaHCO}_{3}, 5 \mathrm{mM}$ HEPES, pH 7.4). Each hemorphin was diluted for a final concentration of $100 \mu \mathrm{M}$ in transport medium-LY and applied to the apical chamber $(0.5 \mathrm{~mL} ; 1.5 \mathrm{~mL}$ transport medium in basal chamber) at t0. A test was performed without cells to insure that the filter membrane was not preventing the passage of the peptides. At each time point, $200 \mu \mathrm{L}$ samples were collected in the basal chamber for the LY assay (measured with Synergy H1, BioTek) and the remaining $1.3 \mathrm{~mL}$ were collected at $30 \mathrm{~min}$ and frozen at $-80^{\circ} \mathrm{C}$ for further LC-MS/MS analyses.

\section{LC-MS/MS}

LC-MS/MS analysis was performed on a UFLC-XR device (Shimadzu, Kyoto, Japan) coupled to a QTRAP ${ }^{\circledR} 5500$ MS/MS hybrid system triple quadrupole/linear ion trap mass spectrometer (AB Sciex, Foster City, CA, USA) equipped with a Turbo VTM ion source. Instrument control, data acquisition, and processing were performed using Analyst 1.5.2 software. The reverse phase liquid chromatography separation was carried out on a Kromasil C18 column $(100 \times 2.1 \mathrm{~mm}, 3.5 \mu \mathrm{m})$ with guard cartridge from 
AIT-France (Houilles, France). The injection volume was $2 \mu \mathrm{L}$. Elution was performed at a flow rate of $200 \mu \mathrm{L} \mathrm{min} \mathrm{mith}^{-1}$ waterformic acid $0.1 \%$ as eluent $\mathrm{A}$ and acetonitrile-formic acid $0.1 \%$ as eluent $\mathrm{B}$. The injection duty cycle was $10 \mathrm{~min}$, starting with a 1 min plateau with $25 \% \mathrm{~B}$, followed by a linear gradient from 25 $\mathrm{B}$ to $60 \% \mathrm{~B}$ in $4 \mathrm{~min}$, a $1 \mathrm{~min}$ plateau with $60 \% \mathrm{~B}, 1 \mathrm{~min}$ linear gradient from 60 to $25 \% \mathrm{~B}$, and $3 \mathrm{~min}$ at $25 \% \mathrm{~B}$ to recondition the column. MS analysis was carried out in positive ionization mode. The ion source parameters were optimized and set as follows: ion spray voltage, 5,500 V; nebulizer gas (air) and curtain gas (nitrogen) flows, 50 and 25 psi, respectively; source temperature, $550^{\circ} \mathrm{C}$ with the auxiliary gas flow (air) set at $50 \mathrm{psi}$; declustering potential (DP), $100 \mathrm{~V}$; and collision cell exit potential, $25 \mathrm{~V}$. The mass spectrometer was operated at a unit resolution for both Q1 and Q3 with a dwell time of $90 \mathrm{~ms}$ in each transition.

The presence of each intact hemorphin and potential fragments were tracked by a combination of multiple reaction monitoring (MRM) and pseudo-MRM transitions. V-H4 and $\mathrm{N}$-extended-H3 fragments were not searched because they probably present poor OR ligand capacity (32) and they have not been reported as present in body fluids or tissues.

\section{Radiobinding}

The potential binding of each opioid peptide/hemorphin on OPs was assessed in a radiobinding competition test with $\mathrm{H} 3$-naloxone as the tritiated-specific ligand on rat brain membrane preparation. The protocol used follows the one described in Garreau et al. (9) with some modifications. Briefly, rat brains were homogenized in $50 \mathrm{mM}$ Tris- $\mathrm{HCl}$ added with $240 \mathrm{mM}$ sucrose, $5 \mathrm{mM} \mathrm{MgCl}_{2}$, and $2 \mathrm{mM}$ EDTA and centrifuged first at $1,000 \mathrm{~g}$ for $5 \mathrm{~min}$ at $4^{\circ} \mathrm{C}$. Supernatants were then centrifuged at $30 \times 10^{3} \mathrm{~g}$ for $30 \mathrm{~min}$ at $4^{\circ} \mathrm{C}$ and the resulting pellets were solubilized in the homogenization buffer. Protein dosage was performed with the Sigma QuantiPro BCA Assay Kit. Serial dilutions of each peptide or naloxone as positive control were realized in $50 \mathrm{mM}$ Tris- $\mathrm{HCl}$ buffer $\mathrm{pH} 7.4$ supplemented with $2 \%$ bovine serum albumin and incubated in $0.9 \mathrm{mg} \mathrm{mL}^{-1}$ of rat brain membrane preparation added with the proteases inhibitors bestatin $(10 \mu \mathrm{M}$ final $)$ and thiorphan $(0.1 \mu \mathrm{M}$ final), and $1 \mathrm{nM}$ final $\mathrm{H} 3$-naloxone for $30 \mathrm{~min}$ at $25^{\circ} \mathrm{C}$. Nonspecific binding was determined by adding an excess of naloxone $\left(5 \times 10^{-6} \mathrm{M}\right.$ final) instead of the peptide or naloxone dilutions. All conditions were run in duplicates. At the end of the incubation, separation of bound and unbound samples was realized by vacuum filtration through glass microfiber GF/B filters. Filters were inserted into scintillation vials, added with $3 \mathrm{~mL}$ Optiphase HiSafe 2 scintillation liquid, and radioactivity was counted on a beta-counter (Hidex 300 SL, Sciencetec, Villebon-sur-Yvette, France). Non-specific binding was subtracted from all values and specific binding was expressed as a percentage of total-specific binding $(\mathrm{dpm})$. Competition binding curves were plotted in GraphPad Prism v6.01 and $\mathrm{ED}_{50}$ were determined by non-linear regression analysis.

\section{cAMP Determination Assay}

The effect of the five opioid peptides/hemorphins on the cAMP production was assessed in vitro in Caco-2 cells. Each hemorphin was applied on Caco-2 cells stimulated or not by FK, an activator of the cAMP pathway, in order to evaluate the ability of the peptides to decrease intracellular cAMP elevation induced by FK. Cells were seeded at $1 \times 10^{5}$ cells/well in 24 -well plates and grown for 7 days in complete culture medium. The medium was renewed $24 \mathrm{~h}$ before the test and replaced by the incubation medium, DMEM supplemented with 1\% L-glutamine (DMEML-glu) $30 \mathrm{~min}$ prior to the test start. Each hemorphin was applied at 50,500, or 5,000 $\mu \mathrm{M}$ (FK-stimulated condition) and 50 or $500 \mu \mathrm{M}$ (non-stimulated condition) for $15 \mathrm{~min}$ at $37^{\circ} \mathrm{C}$. The specific OR agonist DAMGO (1 and $100 \mathrm{nM}$ ) and the OR antagonist naloxone $(1 \mu \mathrm{M})$ were tested in the same conditions. To verify that the hemorphin-induced effect on cAMP production was mediated through the activation of OPs, cells were pre-incubated for 30 min with $1 \mu \mathrm{M}$ naloxone in DMEM-L-glu prior to the incubation with each opioid peptide $(500 \mu \mathrm{M})$ or DAMGO (100 nM) in DMEM-L-Glu-FK in the same conditions as previously. All conditions were run in triplicate. At the end of the $15 \mathrm{~min}$ incubation, cells were immediately rinsed three times with $\mathrm{PBS}$ and plates were stored at $-80^{\circ} \mathrm{C}$ until intracellular cAMP levels determination with the Mouse/Rat cAMP Parameter Assay Kit according to the manufacturer's guidelines. cAMP levels were normalized by the total protein concentration determined by the Pierce BCA Protein Assay Kit for each sample and expressed as a percentage of the reference condition FK only.

\section{Gene Expression Analysis}

The impact of opioid peptides on claudin-4 gene expression in Caco- 2 cells was evaluated by qPCR. Caco- 2 were seeded at $80 \times 10^{3}$ cells $\mathrm{cm}^{-2}$ in cell culture inserts into 6 -well culture plates and first cultured in complete DMEM for 3 weeks with media changes (basal and apical) every 2-3 days. $100 \mu \mathrm{M}$ of each hemorphin in DMEM-L-glu or incubation buffer only were applied in triplicate in the apical compartment for $24 \mathrm{~h}$ at $37^{\circ} \mathrm{C}, 5 \% \mathrm{CO}_{2}$. At the end of the incubation time, cells were rinsed two times in PBS and scrapped in TRI Reagent. Total RNA was further isolated and processed according to the protocol described in Caron et al. (15). qPCR analyses were performed with specific oligonucleotides for claudin-4: forward (F) 5'-CCACTCGGACAACTTCCCAA- ${ }^{\prime}$ ' and reverse (R) 5'-ACT TCCGTCCCTCCCCAATA-3', and peptidylprolyl isomerase

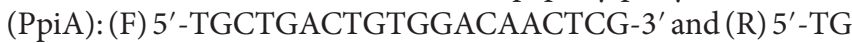
CAGCGAGAGCACAAAGAT-3' and the Power SYBR Green PCR Master Mix on a StepOne ${ }^{\mathrm{TM}}$ Plus system (Applied BioSystems, Life Technologies). mRNA fold induction was calculated according to the $2^{-\Delta \Delta \mathrm{Ct}}$ method ( $\Delta \Delta \mathrm{Ct}$ method, Applied Biosystems User Bull. \#2 Dec. 97) using PpiA as internal control (reference gene) and expressed as a percentage of the control group induction.

\section{Statistical Analysis}

Data presented are mean \pm SD. Statistical analysis was conducted in GraphPad prism v6.1. One-way ANOVA was applied with Tukey or Dunnett's test for post hoc analyses. For comparison of the cAMP levels, a two-way ANOVA was used to consider the different concentrations used, followed by a Dunnett's test for multiple comparisons. To assess the effect of the naloxone treatment 
in the complementary cAMP assay, a two-way ANOVA was used, and each hemorphin effect was compared to its corresponding naloxone treatment by a Sidak test. The Dunnett's post hoc test was used for DAMGO comparisons. Significance level was set at $p<0.05$.

\section{RESULTS}

\section{IB Passage}

In first analysis, the samples collected at each time point in the basal compartment below the Caco-2 cells layer modeling the IB were analyzed by LC-MS/MS with MRM to detect the whole peptide sequences. The analysis revealed that LVV- and $\mathrm{VV}-\mathrm{H} 4$ as well as $\mathrm{H} 7$ were clearly able to cross intact the cell monolayer, whereas VV-H7 was found in traces and LLVV-H4 was not detected (Figure 1). H7 displayed the most rapid passage as it appeared basally as soon as 5 min incubation and its basal concentration increased faster. LVV- and VV-H4 appeared in the 60 min samples and behaved similarly. All peptides except the LLVV-H4 sequence were still found intact and abundant in the apical side after $120 \mathrm{~min}$ incubation (Figure 1).

Nevertheless, in addition to the intact peptides, potential fragments all comprising the tripeptide YPW were then searched in each basal sample by LC-MS/MS with pseudoMRM. Expectedly, the peptides with an N-terminal extension were hydrolyzed and gave the other peptide sequences under investigation (e.g., in the well where LLVV-H4 was applied, LVV- and VV-H4 were found as well). However, although LVVand VV-H4 were able to cross the cell barrier when applied alone, they were not found in the basal side of the LLVV-H4 wells, where they were produced apically. Interestingly, for all tested peptides the most abundant fragment identified is the tetrapeptide core YPWT (Figure 2).

Results from the LY passage monitoring indicated that the integrity of the cell monolayer was not altered throughout the 120 min incubation (Figure 3). Papp values calculated were all below $1 \times 10^{-6} \mathrm{~cm} \mathrm{~s}^{-1}$ which is a commonly accepted threshold for barrier integrity. However, though not statistically significantly different from the control value (as assessed by Dunnett's post hoc analysis), peptides LY Papp values seemed to correlate with the ability of the hemorphins to cross the cell barrier. Indeed, peptides with Papp(LY) values similar or above the control one showed the most passage. This was the most striking for $\mathrm{H} 7 \mathrm{for}$ which Papp(LY) was almost six times higher than control one $\left(7.632 \mathrm{e}-007 \pm 6.504 \mathrm{e}-007>1.310 \mathrm{e}-007 \pm 6.308 \mathrm{e}-008 \mathrm{~cm} \mathrm{~s}^{-1}\right.$, $p=0.0503$ ), whereas LLVV-H4 and VV-H7 which did not or barely crossed the barrier displayed Papp(LY) decreased compared to control (non-significant).

\section{BBB Passage}

The same LC-MS/MS analyses were applied on the samples collected during the test of passage of the hemorphins across the co-culture layer modeling the BBB. The analyses revealed that all peptides were able to cross intact this cell barrier (Figure 4). In comparison to the IB model, the transport was faster and more efficient, since all hemorphins were detected basally already at 30 min of incubation and the passage occurred despite a much lower initial apical concentration, i.e., $100 \mu \mathrm{M}$ in the BBB model vs $5 \mathrm{mM}$ in the IB model.

The search for the peptides fragments yielded partially the same results. The same fragments were identified except the fragment YPWTQ which was only detected in the basal VV-H7 and $\mathrm{H} 7$ samples of the $\mathrm{BBB}$ co-culture model. Moreover, the fragment YPWT was also found basally in all samples. In contrast to the results of the IB test, YPWT was not the main fragment and longer ones were also found in the basal compartment.

With regards to the LY permeability, LLVV-H4 and VV-H4 significantly increased Papp(LY) compared to control (Dunnett's post hoc analysis: $133.2 \pm 16.44 \%, p=0.0446$ and $142.2 \pm 26.71 \%$, $p=0.0106$, respectively) without affecting the cell barrier integrity (Figure 5). This was reflected by the Papp values that were all below $1 \times 10^{-6} \mathrm{~cm} \mathrm{~s}^{-1}$ which is a commonly accepted threshold for barrier integrity.

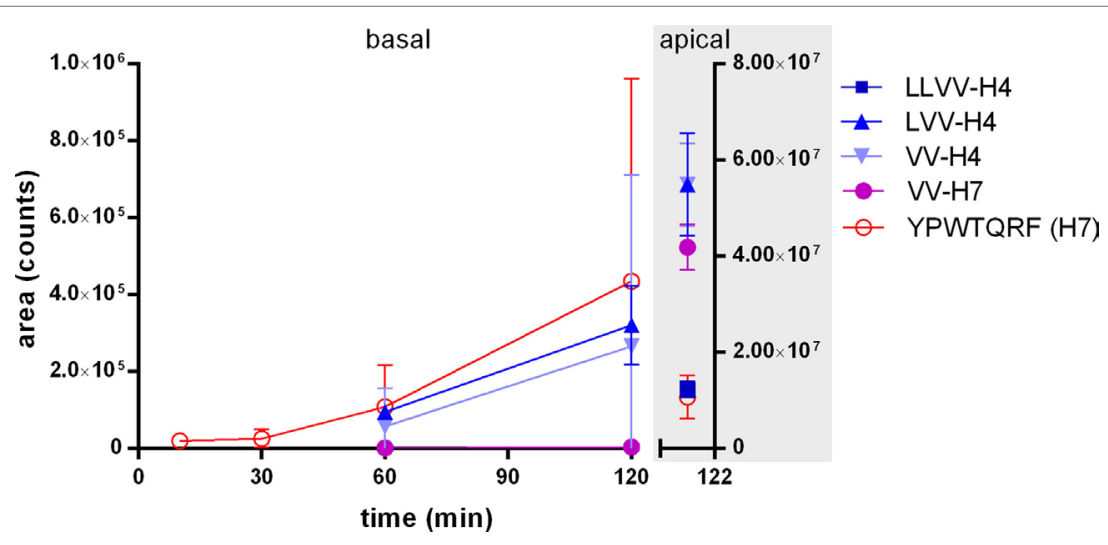

FIGURE 1 | Appearance kinetics of the five hemorphins intact in the basal side of Caco-2 monolayer as an intestinal barrier (IB) passage model. The passage of the five hemorphins was tested in the Caco-2-transwell model of the IB. Each peptide was separately applied at $5 \mathrm{mM}$ in the apical chamber of a transwell and the appearance of the intact peptide was monitored by LC-MS/MS with multiple reaction monitoring in the basal chamber at five time points. The graph also shows the remaining intact peptides in the apical chamber after $2 \mathrm{~h}$ incubation. Data are expressed as mean $\pm \mathrm{SD}(n=3)$. 

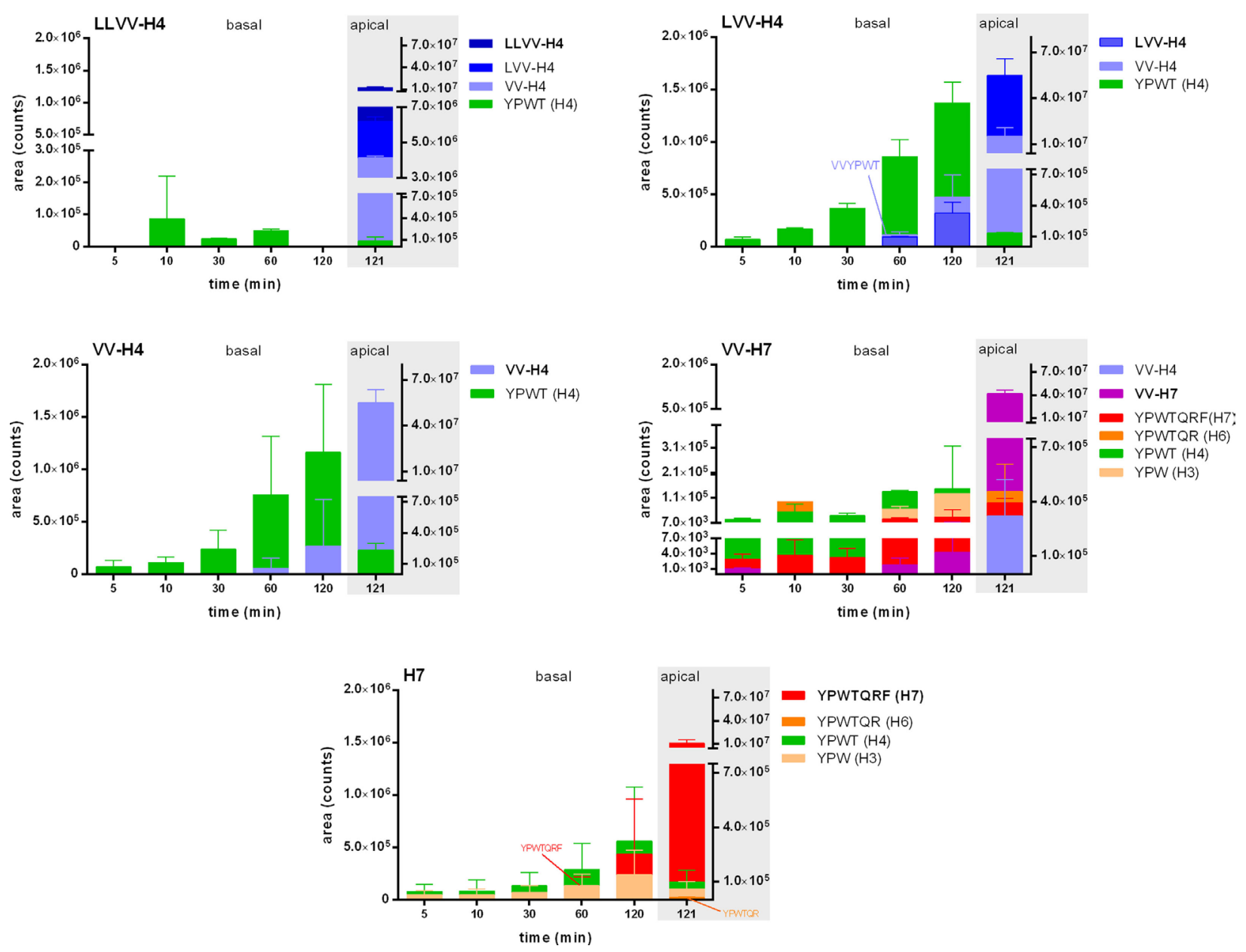

FIGURE 2 | Release kinetics of the five hemorphins fragments in the basal side of a Caco-2 monolayer as an intestinal barrier passage model. The metabolism of the five hemorphins was evaluated by monitoring the apparition of peptide fragments issued from the opioid peptides by selected ion monitoring analyses in the basal chamber at five time points. The presence of these fragments was also investigated in the apical chamber after the $2 \mathrm{~h}$ incubation to determine whether these fragments were the results of the passage through the Caco-2 monolayer. Data are expressed as mean \pm SD $(n=3)$.

\section{OP Binding}

The determination of the OP-binding capacity of each hemorphin was performed on rat brain membrane preparation. The binding capacity of peptide LLVV-H4 could not be determined in the same conditions as for the other peptides, since its solubility was poor in the incubation buffer at concentrations higher than $5 \times 10^{-5} \mathrm{M}$. Especially because of the method of separation of the bound and unbound ligands on glass microfiber filters; we suspected that the peptide dilution clogged the filter. Nevertheless, at least for the $10^{-10}$ to $10^{-4} \mathrm{M}$ range (data not shown) LLVV-H4 was not able to compete with the specific OR tritiated antagonist. In contrast, all other tested hemorphins were able to decrease the fixation of the ${ }^{3} \mathrm{H}$-naloxone on OPs in a dose-dependent manner. Inhibition of the antagonist binding on OR was efficient in the $5 \times 10^{-7}$ to $5 \times 10^{-3} \mathrm{M}$ range for $\mathrm{H} 7$ and in the $5 \times 10^{-5}$ to $5 \times 10^{-3} \mathrm{M}$ range for the other hemorphins (Figure 6). Thus, except for H7, the binding curves display a steep decrease within 2 log units of hemorphins concentrations suggesting a competition for a single binding site. $\mathrm{H} 7$ binding curve displayed a shallower decrease on nearly 4 log units that could be indicative of a competition for more than one binding site.

As illustrated by the competitive binding curve and the determination of $\mathrm{IC}_{50}$, the affinity of the hemorphins ranked as follows from the most affinity to the least: $\mathrm{H} 7>\mathrm{VV}-\mathrm{H} 7>\mathrm{LVV}$ $\mathrm{H} 4>\mathrm{VV}-\mathrm{H} 4$ (Figure 6 inset). The presence of the N-terminal extension impaired or reduced binding (compared to the C-terminal only extension), since peptides with an N-terminal extension only displayed the highest $\mathrm{IC}_{50}$ and the peptide VV-H7 with both $\mathrm{N}$ - and $\mathrm{C}$-terminal extensions presented an intermediary $\mathrm{IC}_{50}$.

\section{cAMP Pathway Activation}

In order to precise the OR agonist, antagonist or mixed nature of the hemorphins, their effect on the accumulation of intracellular cAMP in Caco-2 cells upon stimulation with an activator of adenylate cyclase, FK, was investigated. OR agonists have a known inhibitory action on adenylate cyclase with a consecutive reduction of intracellular cAMP formation (33). Measurement 
of intracellular cAMP under different concentrations of each hemorphin in FK-stimulated cells did not show a clear dose effect. The highest tested concentration of $5 \mathrm{mM}$ did induce a significant decrease in FK-stimulated cAMP concentration compared to control levels for all sequences, except LLVV-H4, and is indicative of an agonist-like behavior of the hemorphins (Figure 7A). The highest reductions were achieved by LVV-H4, $50 \%(49.57 \pm 14.79 \%$ of FK levels, $p<0.001)$ and H7, $47 \%$ $(53.24 \pm 17.41 \%$ of FK levels, $p<0.001)$, while VV-H4 induced a reduction of $35 \%(64.56 \pm 7.67 \%$ of FK levels, $p=0.0009)$ and VV-H7 of $28 \%$ (72.01 $\pm 26.42 \%$ of FK levels, $p=0.0104)$.

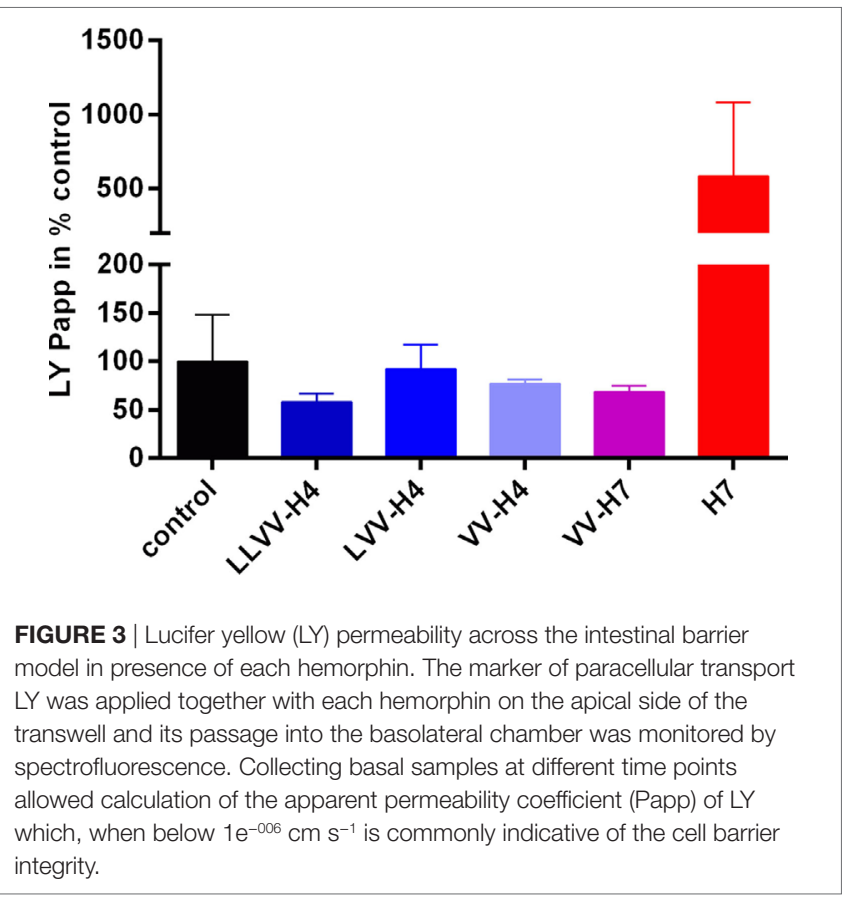

Notably, H7 was able to inhibit FK-induced cAMP elevation (of about $30 \%$ ) at the two other lower concentrations of 500 and $50 \mu \mathrm{M}(72.38 \pm 13.25 \%, p=0.0117$ and $70.96 \pm 14.58 \%$ of $\mathrm{FK}$ levels, $p=0.0075$, respectively). Thus, $5 \mathrm{mM}$ of LVV-H4 and $\mathrm{H} 7$ produced a decrease in the same size range, about $50 \%$, as following the specific MOR agonist DAMGO incubation at 1 and $100 \mathrm{nM}(50.30 \pm 9.71 \%, p=0.0001$ and $55.56 \pm 24.20 \%$ of FK levels, $p=0.0005$, respectively). DAMGO did not present dosedependent effect either. Very surprisingly, naloxone, a specific, but non-selective OR antagonist did also significantly decrease FK-induced cAMP elevation $(68.42 \pm 6.87 \%$ of FK levels, $p=0.0394)$ when incubated alone at $1 \mu \mathrm{M}$ with Caco- 2 cells.

To confirm that the effect of hemorphins on cAMP production involves OR, we treated FK-stimulated cells with each hemorphin at $500 \mu \mathrm{M}$ separately with or without naloxone at $1 \mu \mathrm{M}$. Unexpectedly, the naloxone treatment, when concomitant to hemorphins incubation, promoted a dramatically significant increase in FK-induced cAMP elevation (Figure 7B). It potentiated the FK effect on CAMP formation by at least $50 \%$ for each tested hemorphin as well as for DAMGO, and 38\% for LVV-H4. Sidak post hoc analysis of each hemorphin or DAMGO treatment compared to its corresponding hemorphin or DAMGO and naloxone co-treatment yielded a statistically significant increase of cAMP of $93 \%$ for VV-H4 $(p=0.0006), 74 \%$ for VV-H7 $(p=0.0058), 93 \%$ for H7 $(p=0.0006)$, and $108 \%$ for DAMGO $(p=0.0184)$.

\section{Gene Expression Analysis (Caco-2 Model of IB)}

The potential effect of the five hemorphins on the TJ protein claudin-4 gene expression has been investigated in vitro on Caco-2 cells first grown for 3 weeks on cell culture membranes for full differentiation as epithelium. Quantitative PCR analyses showed that all hemorphins except LVV-H4 induced a significant decrease in claudin- 4 mRNA levels of almost $50 \%$ or more of

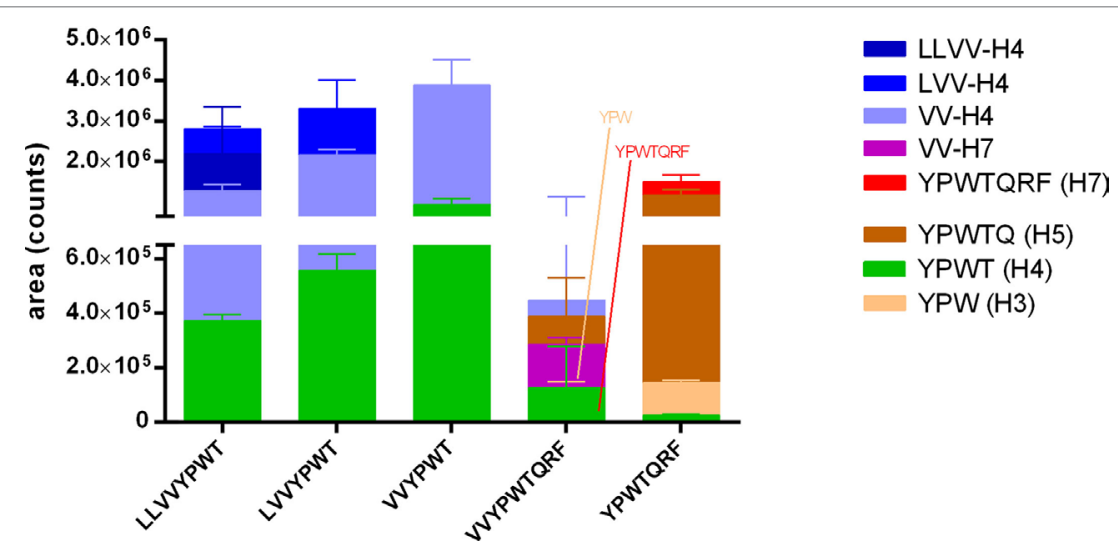

FIGURE 4 | Passage of the five hemorphins intact or their fragments across the brain-like endothelial cell blood-brain barrier (BLEC) model. The passage of the five hemorphins was tested in the BLEC model (co-culture of hematopoietic CD34+-derived endothelial cells with bovine pericytes). Each peptide was separately applied at $100 \mu \mathrm{M}$ in the apical chamber ("blood" side) of a transwell and the presence of the intact peptides and potential fragments thereof in the basal chamber ("brain" side) was investigated by a combination of LC-MS/MS with multiple reaction monitoring (MRM) and pseudo-MRM analyses after 30 min incubation. Data are expressed as mean $\pm \mathrm{SD}(n=3)$. 
control levels (Figure 8). This effect was more pronounced in cells treated with hemorphins presenting a C-terminal extension than those harboring an $\mathrm{N}$-terminal extension. The hemorphins presenting a C-terminal extension, VV-H7, and H7, reduced mRNA levels to $30.03 \pm 10.99 \%(p=0.0009)$ and $28.31 \pm 2.52 \%$ ( $p=0.0008)$ of control levels, respectively, VV-H4 to a similar extent with $24.74 \pm 13.67 \%(p=0.0005)$ and LVV-H4 to a lesser extent with $52.74 \pm 19.37 \%(p=0.0166)$ of control levels.

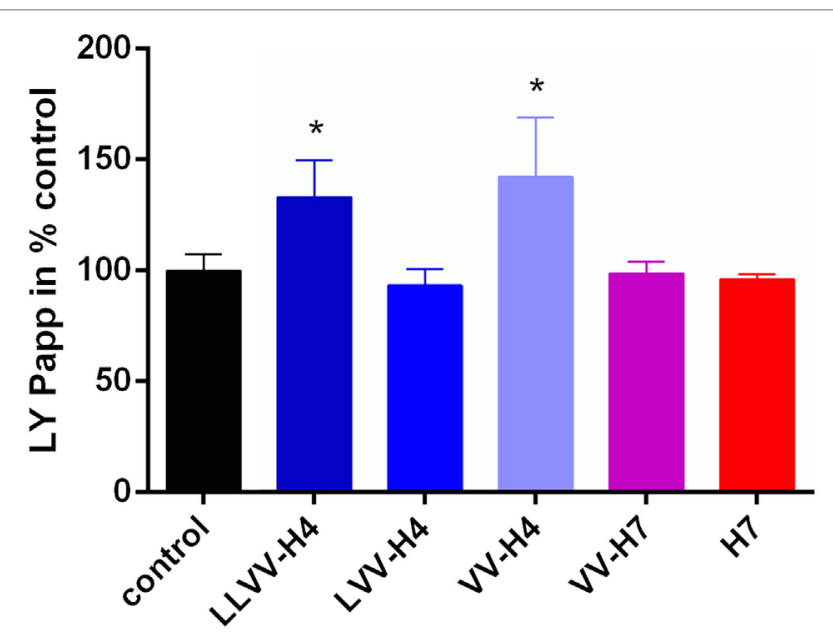

FIGURE 5 | Lucifer Yellow (LY) permeability across the blood-brain barrier model in presence of each hemorphin. The marker of paracellular transport LY was applied together with each hemorphin on the apical side of the transwell and its passage into the basolateral chamber was monitored by spectrofluorescence. Collecting basal samples at different time points allowed calculation of the apparent permeability coefficient (Papp) of LY which, when below $1 \mathrm{e}^{-006} \mathrm{~cm} \mathrm{~s}^{-1}$ is commonly indicative of the cell barrier integrity.

\section{DISCUSSION}

This study is a first report of the passage of food-derived hemorphins, i.e., exogenous hemorphins, through the intestinal as well as the BBB in vitro (Table 1). Information on the in vitro absorption of alimentary proteins or of well-defined peptide sequences derived thereof has been mainly garnered from tests with milk proteins (34-36), much less from tests with whey proteins $(19,37)$, or lately from egg albumin (38) but this information was unknown for hemorphins. The tested peptide the closest in terms of structure to hemorphins, is endomorphine- 1 for which a low permeability through a caco-2 cell monolayer was reported (39).

We found that all hemorphins except the LLVV-H4 sequence could cross intact the Caco- 2 cell monolayer. A possible explanation for the failure of passage of this sequence is brush-border enzymes degradation. The presence of multiple fragments in both apical and basal compartments may suggest that the peptides interacted with brush-border, basolateral, or intracellular peptidases (Figure 2). Indeed, LVV-H4, VV-H4, and $\mathrm{H} 4$ fragments and no LLVV-H4 detection in the apical compartment at the end of the experiment could reflect that LLVV-H4 was hydrolyzed to such an extent that no passage to the basal compartment occurred. It is recognized that the primary factor limiting transepithelial transport of intact peptides and its bioavailability is the susceptibility to cellular peptidases (40). This can reflect that the transport is probably concentration-dependent, since this was not the case in the LVV-H4 wells, where the fragment VV-H4 was detected both in apical and basal compartments. This does not exclude that this latter fragment is produced from LVV-H4 in apical and basal. However, the Caco-2 model is acknowledged as quite a stringent test for in vitro IB passage, meaning that results obtained in this test rather underestimate in vivo human IB passage (41).

Regarding the passage of the $\mathrm{BBB}$, though applied at a much lower concentration than in the IB/Caco-2 test $(100 \mu \mathrm{M}$ vs

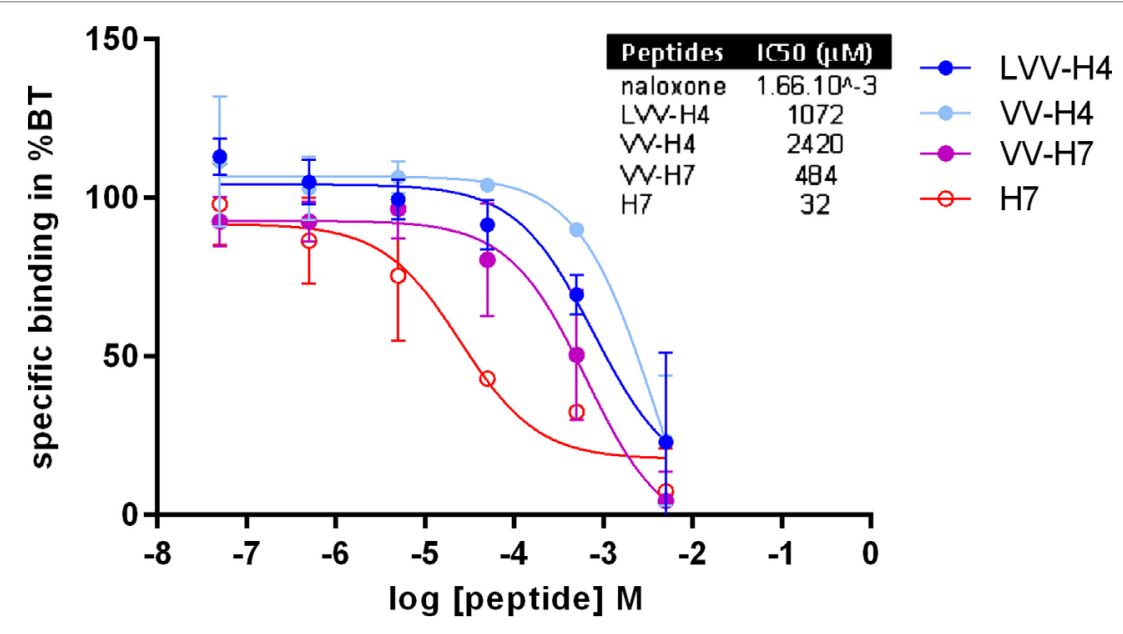

FIGURE 6 | Determination of hemorphins binding to rat brain membranes opioid receptors (OPs). The ability of the hemorphins/opioid peptides to bind to OPs was assessed in a radiobinding assay in vitro by competition with $\mathrm{H} 3$-naloxone (non-selective OP antagonist) on rat brain membrane preparation. Six concentrations ranging from $5 \times 10^{-8}$ to $5 \times 10^{-3} \mathrm{M}$ were tested in duplicates and the results were expressed as a percentage of total binding without opioid peptides. Inset: dose-response curves were analyzed in GraphPad Prism 6 by non-linear regression from which IC 50 were interpolated. Data presented are mean (average of two separate assays) \pm SD. 

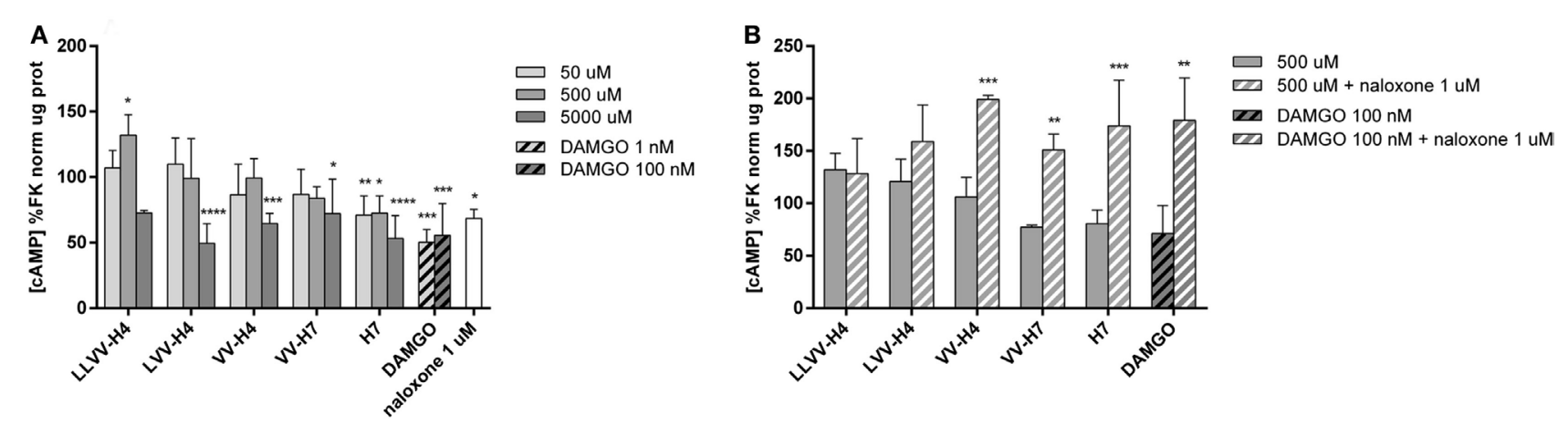

FIGURE 7 | Determination of intracellular cAMP in forskolin (FK)-stimulated Caco-2 cells after incubation with the five hemorphins. (A) The ability of the hemorphins/ opioid peptides to act on the CAMP pathway was evaluated in vitro. Caco-2 cells were incubated with or without increasing concentrations of each hemorphin, DAMGO, a known specific OP agonist and naloxone, a known OP antagonist, in FK-supplemented medium for 15 min at $37^{\circ} \mathrm{C}$. Intracellular cAMP levels were determined by ELISA, normalized by the total protein concentration and expressed as a percentage of the reference group FK. Data presented are mean \pm SD (average of two assays performed in triplicate; $n=6$ ). ${ }^{\star}$ Statistically different from control; ${ }^{*} p<0.05$, ${ }^{* *} p<0.01$, ${ }^{\star * *} p<0.005$. (B) To determine whether the effect of the hemorphins was mediated through OPs, the same assay was performed with or without naloxone (1 $\mu \mathrm{M})$ in the same incubation medium. Data presented are mean $\pm \operatorname{SD}(n=3)$. * Statistically different from control; ${ }^{* *} p<0.01$, ${ }^{\star \star *} p<0.005$

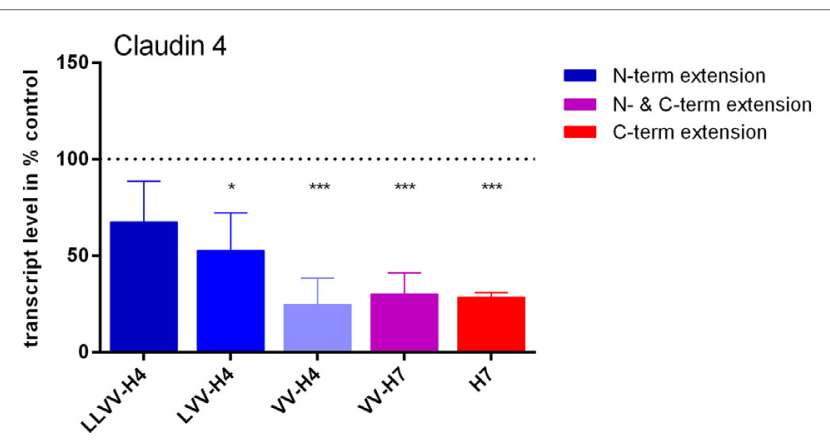

FIGURE 8 | Effect of the five hemorphins on claudin-4 mRNA levels in the Caco-2 cells intestinal barrier (IB) model. Caco-2 cells were seeded on the filter of cell culture insert and cultured for 3 weeks until full differentiation as in the IB model. They were then incubated with $100 \mu \mathrm{M}$ of each hemorphin/ opioid peptide in culture medium for $24 \mathrm{~h}$. Total RNAs were isolated and processed for quantitative real-time PCR analyses. Claudin- 4 transcript levels were normalized by reference gene peptidylprolyl isomerase transcript levels and expressed as \% of control levels (without opioid peptides). Experiments were run in triplicate and data represented are mean \pm SD. *Statistically different from control; ${ }^{\star} p<0.05,{ }^{\star \star \star} p<0.005$.

$5 \mathrm{mM}$ ), all tested hemorphins proved to be able to cross intact the modeled BBB in vitro. Concentrations tested in each model were chosen according to a literature search among Caco-2 studies of compounds permeability. It yielded a range of concentrations tested between few hundreds of $\mu \mathrm{M}$ to few $\mathrm{mM}\left(100-500 \times 10^{-4}\right.$ to $10 \times 10^{-3} \mathrm{M}$ ). A first trial concentration of $300 \mu \mathrm{M}$ in the IB passage test resulted in no detectable recovery of the intact peptides in the basal compartment (data not shown). Given that if the hemorphins do cross the IB, they do so in very low amounts, therefore, it was physiologically relevant to test much lower concentrations in the $\mathrm{BBB}$ passage test. Moreover, in the $\mathrm{BBB}$ passage test, all intact hemorphins were detected in the basal compartment $30 \mathrm{~min}$ after their apical application in comparison to $60 \mathrm{~min}$ in the Caco-2 model, except for $\mathrm{H} 7$ which was detected already at $5 \mathrm{~min}$ in this latter model. In agreement with our results, the $\mathrm{BBB}$ passage of $\mathrm{H} 7$ had been demonstrated in a study using ${ }^{125} \mathrm{I}-\mathrm{H} 7$ in rats within $15 \mathrm{~min}$ of intra-femoral artery injection (42). However, a study comparing 18 peptides permeability through the $\mathrm{BBB}$ in rats in relation to their amino-acid structure and different physico-chemical properties (43) reported that $\mathrm{N}$-terminal tyrosine constitutes a brake to $\mathrm{BBB}$ passage, yet $\mathrm{H} 7$ which presents such residue was clearly able to cross the in vitro BBB model in this study.

In addition, we show that fragments of the tested hemorphins were also able to pass the Caco- 2 epithelium as well as the modeled BBB (Table 1) and that is interesting inasmuch as these fragments retain a certain bioactivity, like the OP-binding capacity. Strikingly, the most frequent hemorphin fragment recovered is the core tetrapeptide YPWT (H4), common to all tested hemorphins. Three pieces of evidence would indicate that YPWT is produced in the apical compartment by hydrolysis of the hemorphins and is able to cross the cell barrier. First, the fragment YPWT was identified in the basal samples as soon as $5 \mathrm{~min}$ incubation either before the parent peptide was even detected (LVV- and VV-YPWT) or at the same time (VV-YPWT-QRF and YPWT-QRF). Second, for LLVV-H4 wells, the parent peptide was seemingly not able to cross the cell barrier and for VV-H7, only traces were detected basally. Finally, $120 \mathrm{~min}$ apical amounts of YPWT were notably lower than basal ones. H4 was the first hemoglobin-derived opioid peptide identified as such (8) and also has the feature to be very stable in plasma.

In this regard, we verified the OR-binding capacity of the hemorphins synthesized for this study on rat brain membrane preparation. Our results add the sequence LVV-H4 as OR ligand, which, to the best of our knowledge, had not been tested for its opioid activity. Also, our results are in agreement with the findings of Zhao et al. (32) showing that $\mathrm{N}$-extensions on the $\mathrm{H} 4$ core tend to disfavor OP-binding, whereas C-extensions tend to increase it.

We further sought to characterize the agonist/antagonist nature of the hemorphins in the cAMP assay commonly used for 
OR-ligand investigation. Multiple studies realized mostly with mu-OR agonists in different cell lines found that OR agonism resulted in a decrease of intracellular cAMP formation $(33,39,44)$. Here, however, unexpected results were found with the naloxone treatment which is a well-known non-selective OR antagonist. Naloxone alone yielded decreased cAMP levels in FK-stimulated Caco-2 cells and potentiated CAMP increase when applied with each hemorphin (Figure 7). A comparable result was reported with naloxone in a different cell line as Fukuda et al. (45) showed that naloxone can have a partial agonist activity in mu- and kappa-transfected $\mathrm{CHO}$-cells. Also, $\mathrm{H} 4$ was found as agonist in the GPI bioassay, but antagonist when applied in the ileum from a morphine-tolerant rat (i.e., after a morphine pre-treatment) (11). Hence, our results regarding the effect of hemorphins on the cAMP pathway in Caco-2 cells are compatible with an interaction with OR, but may also be indicative of the involvement of other G-protein-coupled receptors. Considering that hemorphins and naloxone effects separately inhibited FK-induced cAMP elevation, these results suggest a synergistic effect of hemorphins and naloxone on the cAMP pathway. Although performance of the cAMP assay in Caco-2 cells is not classical, this choice was justified by the use of these cells in the IB model and would thus allow us to infer some evidence regarding the underlying mechanisms of the hemorphins effects on TJs.

Indeed, hemorphins were suspected of passing the IB epithelium by interaction with the TJ. There is some evidence that some substances are able to alter intestinal permeability via their action on TJ proteins $(40,46,47)$. TJ may be regulated by phosphorylation that promotes or decreases permeability. For instance, in low resistance cells the TJ protein $\mathrm{ZO}-1$ is significantly more phosphorylated than in high resistance monolayers (48). Also, it has been shown that the phosphorylation of claudin- 4 enhanced paracellular permeability in HT29 colon cells (49). Hence, our results support the potential action of hemorphins via OR and the cAMP pathway to modulate claudin and other TJ proteins at least in intestinal epithelial cells.

However, hemorphins could also have a long-term effect on TJ proteins that is related to the implication of claudins in intestinal

\section{REFERENCES}

1. Glämsta EL, Meyerson B, Silberring J, Terenius L, Nyberg F. Isolation of a hemoglobin-derived opioid peptide from cerebrospinal fluid of patients with cerebrovascular bleedings. Biochem Biophys Res Commun (1992) 184(2): 1060-6. doi:10.1016/0006-291X(92)90699-L

2. Karelin AA, Philippova MM, Karelina EV, Ivanov VT. Isolation of endogenous hemorphin-related hemoglobin fragments from bovine brain. Biochem Biophys Res Commun (1994) 202(1):410-5. doi:10.1006/bbrc.1994.1943

3. Yatskin ON, Philippova MM, Blishchenko EY, Karelin AA, Ivanov VT. LVVand VV-hemorphins: comparative levels in rat tissues. FEBS Lett (1998) 428(3):286-90. doi:10.1016/S0014-5793(98)00549-3

4. Cejka J, Zelezná B, Velek J, Zicha J, Kunes J. LVV-hemorphin-7 lowers blood pressure in spontaneously hypertensive rats: radiotelemetry study. Physiol Res (2004) 53(6):603-7.

5. Fruitier-Arnaudin I, Cohen M, Bordenave S, Sannier F, Piot J-M. Comparative effects of angiotensin IV and two hemorphins on angiotensinconverting enzyme activity. Peptides (2002) 23(8):1465-70. doi:10.1016/ S0196-9781(02)00083-9 pathologies when their expression or localization is altered (50). We show here that concentrations as low as $100 \mu \mathrm{M}$ of each hemorphin could decrease the gene expression of claudin- 4 in intestinal Caco-2 cells after 24 h of contact (Figure 8).

The digestion of dietary proteins produces peptides that have biological activities, here hemorphins that present OP-binding capacity [see also their intestinal luminal effects in Domenger et al. (16)]. These biopeptides, that resist digestion, also proved to be able to cross the intestinal and BBBs in in vitro conditions, intact, and as fragments that retain opioid-binding capacity. As such they could interact with peripheral and central OPs and participate in appetite and food intake regulation. Further studies will also specify the mechanisms of passage of these hemorphins, especially their interaction with TJ proteins and their impact on barrier permeability.

\section{AUTHOR CONTRIBUTIONS}

DD participated in all steps of preparation, realization, analyses, and writing of this manuscript. MK performed the LC-MS/MS analyses, MK and J-FG provided guidance in the interpretation of the LC-MS/MS results. VT contributed to the passage tests in the Caco-2 model realization. CL contributed to the passage tests in the BLEC model realization. SL, CL, and FG helped in the critical review and the editing of the manuscript. JL helped in the RIA experiments and in the editing of the manuscript. PD helped in the editing of the manuscript. BC and RR were awarded the funding and helped in the design of the experiments and editing the manuscript.

\section{ACKNOWLEDGMENTS}

This work was supported by a grant of the Nord-Pas-de-Calais Region: "2nd appel à projet, Programme projets émergents." It has also been carried out in the framework of Alibiotech project which is financed by the European Union, the French State, and the French Region of Hauts-de-France. The experiments were partly performed at IUT A which is gratefully acknowledged.

6. Moeller I, Lew RA, Mendelsohn FA, Smith AI, Brennan ME, Tetaz TJ, et al. The globin fragment LVV-hemorphin-7 is an endogenous ligand for the AT4 receptor in the brain. J Neurochem (1997) 68(6):2530-7. doi:10.1046/j. 1471-4159.1997.68062530.x

7. Albiston AL, Pederson ES, Burns P, Purcell B, Wright JW, Harding JW, et al. Attenuation of scopolamine-induced learning deficits by LVV-hemorphin-7 in rats in the passive avoidance and water maze paradigms. Behav Brain Res (2004) 154(1):239-43. doi:10.1016/j.bbr.2004.02.012

8. Brantl V, Gramsch C, Lottspeich F, Mertz R, Jaeger KH, Herz A. Novel opioid peptides derived from hemoglobin: hemorphins. Eur J Pharmacol (1986) 125(2):309-10. doi:10.1016/0014-2999(86)90044-0

9. Garreau I, Zhao Q, Pejoan C, Cupo A, Piot JM. VV-hemorphin-7 and LVVhemorphin-7 released during in vitro peptic hemoglobin hydrolysis are morphinomimetic peptides. Neuropeptides (1995) 28(4):243-50. doi:10.1016/ 0143-4179(95)90028-4

10. Patten GS, Head RJ, Abeywardena MY. Effects of casoxin 4 on morphine inhibition of small animal intestinal contractility and gut transit in the mouse. Clin Exp Gastroenterol (2011) 4:23-31. doi:10.2147/CEG. S16161 
11. Zadina JE, Kastin AJ, Kersh D, Wyatt A. Tyr-MIF-1 and hemorphin can act as opiate agonists as well as antagonists in the guinea pig ileum. Life Sci (1992) 51(11):869-85. doi:10.1016/0024-3205(92)90615-V

12. Davis TP, Gillespie TJ, Porreca F. Peptide fragments derived from the betachain of hemoglobin (hemorphins) are centrally active in vivo. Peptides (1989) 10(4):747-51. doi:10.1016/0196-9781(89)90107-1

13. Ueda H, Matsunaga S, Inoue M, Yamamoto Y, Hazato T. Complete inhibition of purinoceptor agonist-induced nociception by spinorphin, but not by morphine. Peptides (2000) 21(8):1215-21. doi:10.1016/S0196-9781(00) 00262-X

14. Yamamoto Y, Ono H, Ueda A, Shimamura M, Nishimura K, Hazato T. Spinorphin as an endogenous inhibitor of enkephalin-degrading enzymes: roles in pain and inflammation. Curr Protein Pept Sci (2002) 3(6):587-99. doi:10.2174/1389203023380404

15. Caron J, Domenger D, Belguesmia Y, Kouach M, Lesage J, Goossens J-F, et al. Protein digestion and energy homeostasis: How generated peptides may impact intestinal hormones? Food Res Int (2016) 88(Pt B):310-8. doi:10.1016/j. foodres.2015.12.018

16. Domenger D, Caron J, Belguesmia Y, Lesage J, Dhulster P, Ravallec R, et al. Bioactivities of hemorphins released from bovine hemoglobin gastrointestinal digestion: dual effects on intestinal hormones and DPP-IV regulations. J Funct Foods (2017) 36:9-17. doi:10.1016/j.jff.2017.06.047

17. Yeomans MR, Gray RW. Opioid peptides and the control of human ingestive behaviour. Neurosci Biobehav Rev (2002) 26(6):713-28. doi:10.1016/ S0149-7634(02)00041-6

18. Duraffourd C, De Vadder F, Goncalves D, Delaere F, Penhoat A, Brusset B, et al. $\mathrm{Mu}$-opioid receptors and dietary protein stimulate a gut-brain neural circuitry limiting food intake. Cell (2012) 150(2):377-88. doi:10.1016/j. cell.2012.05.039

19. Maggioni M, Stuknytė M, De Luca P, Cattaneo S, Fiorilli A, De Noni I, et al. Transport of wheat gluten exorphins A5 and C5 through an in vitro model of intestinal epithelium. Food Res Int (2016) 88(Pt B):319-26. doi:10.1016/j. foodres.2015.11.030

20. Meng J, Sindberg GM, Roy S. Disruption of gut homeostasis by opioids accelerates HIV disease progression. Front Microbiol (2015) 6:643. doi:10.3389/ fmicb.2015.00643

21. Sharma A, Jamal MM. Opioid induced bowel disease: a twenty-first century physicians' dilemma. Considering pathophysiology and treatment strategies. Curr Gastroenterol Rep (2013) 15(7):334. doi:10.1007/s11894-0130334-4

22. Meng J, Yu H, Ma J, Wang J, Banerjee S, Charboneau R, et al. Morphine induces bacterial translocation in mice by compromising intestinal barrier function in a TLR-dependent manner. PLoS One (2013) 8(1):e54040. doi:10.1371/journal. pone. 0054040

23. Artursson P, Karlsson J. Correlation between oral drug absorption in humans and apparent drug permeability coefficients in human intestinal epithelial (Caco-2) cells. Biochem Biophys Res Commun (1991) 175(3):880-5. doi:10.1016/0006-291X(91)91647-U

24. Hidalgo IJ, Raub TJ, Borchardt RT. Characterization of the human colon carcinoma cell line (Caco-2) as a model system for intestinal epithelial permeability. Gastroenterology (1989) 96(3):736-49. doi:10.1016/S0016-5085(89) 80072-1

25. Smetanová L, Stětinová V, Svoboda Z, Kvetina J. Caco-2 cells, biopharmaceutics classification system (BCS) and biowaiver. Acta Medica (Hradec Kralove) (2011) 54(1):3-8. doi:10.14712/18059694.2016.9

26. Lohmann C, Hüwel S, Galla HJ. Predicting blood-brain barrier permeability of drugs: evaluation of different in vitro assays. J Drug Target (2002) 10(4):263-76. doi:10.1080/10611860290031903

27. Lundquist S, Renftel M, Brillault J, Fenart L, Cecchelli R, Dehouck M-P. Prediction of drug transport through the blood-brain barrier in vivo: a comparison between two in vitro cell models. Pharm Res (2002) 19(7):976-81. doi:10.1023/A:1016462205267

28. Cecchelli R, Aday S, Sevin E, Almeida C, Culot M, Dehouck L, et al. A stable and reproducible human blood-brain barrier model derived from hematopoietic stem cells. PLoS One (2014) 9(6):e99733. doi:10.1371/journal.pone. 0099733

29. Eigenmann DE, Dürig C, Jähne EA, Smieško $M$, Culot M, Gosselet F, et al. In vitro blood-brain barrier permeability predictions for GABAA receptor modulating piperine analogs. Eur J Pharm Biopharm (2016) 103:118-26. doi:10.1016/j.ejpb.2016.03.029

30. Gosselet F. [Modelling of the blood-brain barrier]. Med Sci (2017) 33(4): 423-31. doi:10.1051/medsci/20173304013

31. Dugardin C, Briand O, Touche V, Schonewille M, Moreau F, Le May C, et al. Retrograde cholesterol transport in the human Caco-2/TC7 cell line: a model to study trans-intestinal cholesterol excretion in atherogenic and diabetic dyslipidemia. Acta Diabetol (2017) 54(2):191-9. doi:10.1007/s00592016-0936-Z

32. Zhao Q, Garreau I, Sannier F, Piot JM. Opioid peptides derived from hemoglobin: hemorphins. Biopolymers (1997) 43(2):75-98. doi:10.1002/ (SICI) 1097-0282(1997)43:2<75:AID-BIP2>3.0.CO;2-X

33. Harrison C, McNulty S, Smart D, Rowbotham DJ, Grandy DK, Devi LA, et al. The effects of endomorphin-1 and endomorphin-2 in CHO cells expressing recombinant mu-opioid receptors and SH-SY5Y cells. Br J Pharmacol (1999) 128(2):472-8. doi:10.1038/sj.bjp.0702798

34. Cakir-Kiefer C, Le Roux Y, Balandras F, Trabalon M, Dary A, Laurent F, et al. In vitro digestibility of $\alpha$-casozepine, a benzodiazepine-like peptide from bovine casein, and biological activity of its main proteolytic fragment. J Agric Food Chem (2011) 59(9):4464-72. doi:10.1021/jf104089c

35. Iwan M, Jarmołowska B, Bielikowicz K, Kostyra E, Kostyra H, Kaczmarski M. Transport of micro-opioid receptor agonists and antagonist peptides across Caco-2 monolayer. Peptides (2008) 29(6):1042-7. doi:10.1016/j.peptides. 2008.01.018

36. Osborne S, Chen W, Addepalli R, Colgrave M, Singh T, Tran C, et al. In vitro transport and satiety of a beta-lactoglobulin dipeptide and beta-casomorphin-7 and its metabolites. Food Funct (2014) 5(11):2706-18. doi:10.1039/ c4fo00164h

37. Stuknyte M, Maggioni M, Cattaneo S, De Luca P, Fiorilli A, Ferraretto A, et al. Release of wheat gluten exorphins A5 and C5 during in vitro gastrointestinal digestion of bread and pasta and their absorption through an in vitro model of intestinal epithelium. Food Res Intern (2015) 72:208-14. doi:10.1016/j.foodres.2015.04.002

38. Grootaert C, Jacobs G, Matthijs B, Pitart J, Baggerman G, Possemiers S, et al. Quantification of egg ovalbumin hydrolysate-derived anti-hypertensive peptides in an in vitro model combining luminal digestion with intestinal Caco-2 cell transport. Food Res Int (2017) 99(Pt 1):531-41. doi:10.1016/j. foodres.2017.06.002

39. Koda Y, Del Borgo M, Wessling ST, Lazarus LH, Okada Y, Toth I, et al. Synthesis and in vitro evaluation of a library of modified endomorphin 1 peptides. Bioorg Med Chem (2008) 16(11):6286-96. doi:10.1016/j.bmc.2008. 04.020

40. Satake M, Enjoh M, Nakamura Y, Takano T, Kawamura Y, Arai S, et al. Transepithelial transport of the bioactive tripeptide, Val-Pro-Pro, in human intestinal Caco-2 cell monolayers. Biosci Biotechnol Biochem (2002) 66(2):378-84. doi:10.1271/bbb.66.378

41. Lennernäs H, Palm K, Fagerholm U, Artursson P. Comparison between active and passive drug transport in human intestinal epithelial (caco-2) cells in vitro and human jejunum in vivo. Int J Pharm (1996) 127(1):103-7. doi:10.1016/0378-5173(95)04204-0

42. Sharma HS, Sanderson K, Glämsta E-L, Olsson Y, Nyberg F. Vascular permeability to hemorphins in the central nervous system. In: Couraud P-O, Scherman D, editors. Biology and Physiology of the Blood-Brain Barrier. US: Springer (1996). p. 63-8.

43. Banks WA, Kastin AJ. Peptides and the blood-brain barrier: lipophilicity as a predictor of permeability. Brain Res Bull (1985) 15(3):287-92. doi:10.1016/0361-9230(85)90153-4

44. Varamini P, Mansfeld FM, Blanchfield JT, Wyse BD, Smith MT, Toth I. Synthesis and biological evaluation of an orally active glycosylated endomorphin-1. JMed Chem (2012) 55(12):5859-67. doi:10.1021/ jm300418d

45. Fukuda K, Kato S, Shoda T, Morikawa H, Mima H, Mori K. Partial agonistic activity of naloxone on the opioid receptors expressed from complementary deoxyribonucleic acids in Chinese hamster ovary cells. Anesth Analg (1998) 87(2):450-5. doi:10.1213/00000539-199808000-00041

46. Shimizu M. Interaction between food substances and the intestinal epithelium. Biosci Biotechnol Biochem (2010) 74(2):232-41. doi:10.1271/ bbb. 90730 
47. Shimizu M, Son DO. Food-derived peptides and intestinal functions. Curr Pharm Des (2007) 13(9):885-95. doi:10.2174/138161207780414287

48. Stevenson BR, Anderson JM, Braun ID, Mooseker MS. Phosphorylation of the tight-junction protein ZO-1 in two strains of Madin-Darby canine kidney cells which differ in transepithelial resistance. Biochem J (1989) 263(2):597-9. doi:10.1042/bj2630597

49. Tanaka M, Kamata R, Sakai R. EphA2 phosphorylates the cytoplasmic tail of Claudin-4 and mediates paracellular permeability. J Biol Chem (2005) 280(51):42375-82. doi:10.1074/jbc.M503786200

50. Lu Z, Ding L, Lu Q, Chen Y-H. Claudins in intestines. Tissue Barriers (2013) 1(3):e24978. doi:10.4161/tisb.24978
Conflict of Interest Statement: The authors declare that the research was conducted in the absence of any commercial or financial relationships that could be construed as a potential conflict of interest.

Copyright $\odot 2018$ Domenger, Cudennec, Kouach, Touche, Landry, Lesage, Gosselet, Lestavel, Goossens, Dhulster and Ravallec. This is an open-access article distributed under the terms of the Creative Commons Attribution License (CC BY). The use, distribution or reproduction in other forums is permitted, provided the original author(s) and the copyright owner are credited and that the original publication in this journal is cited, in accordance with accepted academic practice. No use, distribution or reproduction is permitted which does not comply with these terms. 